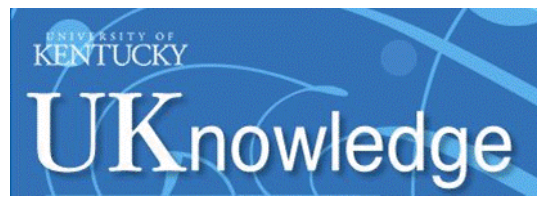

University of Kentucky

UKnowledge

Power and Energy Institute of Kentucky Faculty Publications

Power and Energy Institute of Kentucky

$10-2017$

\title{
MAGNUS--An Ultra-High Specific Torque PM Axial Flux Type Motor with Flux Focusing and Modulation
}

\author{
Vandana Rallabandi \\ University of Kentucky, vandana.rallabandi@uky.edu \\ Narges Taran \\ University of Kentucky, narges.taran@uky.edu \\ Dan M. Ionel \\ University of Kentucky, dan.ionel@uky.edu \\ Ion G. Boldea \\ Universitatea Politehnica Timisoaraand Romanian Academy, Romania
}

Follow this and additional works at: https://uknowledge.uky.edu/peik_facpub

Part of the Power and Energy Commons

Right click to open a feedback form in a new tab to let us know how this document benefits you.

\section{Repository Citation}

Rallabandi, Vandana; Taran, Narges; Ionel, Dan M.; and Boldea, Ion G., "MAGNUS--An Ultra-High Specific Torque PM Axial Flux Type Motor with Flux Focusing and Modulation" (2017). Power and Energy Institute of Kentucky Faculty Publications. 40.

https://uknowledge.uky.edu/peik_facpub/40

This Conference Proceeding is brought to you for free and open access by the Power and Energy Institute of Kentucky at UKnowledge. It has been accepted for inclusion in Power and Energy Institute of Kentucky Faculty Publications by an authorized administrator of UKnowledge. For more information, please contact UKnowledge@lsv.uky.edu. 


\title{
MAGNUS--An Ultra-High Specific Torque PM Axial Flux Type Motor with Flux Focusing and Modulation
}

\author{
Digital Object Identifier (DOI) \\ https://doi.org/10.1109/ECCE.2017.8095930
}

\section{Notes/Citation Information}

Published in 2017 IEEE Energy Conversion Congress and Exposition (ECCE).

(C) 2017 IEEE Copyright Notice. "Personal use of this material is permitted. Permission from IEEE must be obtained for all other uses, in any current or future media, including reprinting/republishing this material for advertising or promotional purposes, creating new collective works, for resale or redistribution to servers or lists, or reuse of any copyrighted component of this work in other works."

The document available for download is the authors' manuscript version that is accepted for publication. The final published version is copyrighted by IEEE and will be available as: V. Rallabandi, N. Taran, D. M. Ionel and I. G. Boldea, "MAGNUS - An ultra-highspecific torque PM axial flux type motor with flux focusing and modulation," Rec. 2017 IEEE Energy Conversion Congress and Exposition (ECCE), Cincinnati, $\mathrm{OH}$, 2017, pp.1234-1239. doi: 10.1109/ECCE.2017.8095930 


\section{MAGNUS - An Ultra-high Specific Torque PM Axial Flux Type Motor with Flux Focusing and Modulation}

\author{
Vandana Rallabandi, Narges Taran, Dan M. Ionel \\ Department of Electrical and Computer Engineering \\ University of Kentucky \\ Lexington, Kentucky, USA \\ Email: vandana.rallabandi@uky.edu,narges.taran@uky.edu,dan.ionel@uky.edu
}

\author{
Ion G. Boldea \\ Department of Electrical Engineering \\ Universitatea Politehnica Timisoara \\ and Romanian Academy, Romania \\ Email: ion.boldea@upt.ro
}

\begin{abstract}
Axial flux permanent magnet (AFPM) synchronous motors are attractive for low speed direct drive systems because of their high specific torque. The present paper proposes a novel axial flux machine topology, called MAGNUS, obtained by combining a yokeless central stator type NS arrangement with two external high polarity spoke-rotors, resulting in very high flux concentration. The stator, which includes main and auxiliary teeth for air-gap profiling has a small number of concentrated coils. Two stator configurations are discussed, the first, a yokeless construction with coils wound around the teeth, and the second with coils placed around the stator core in a Gramme ring arrangement. Feasible slot pole combinations are identified. High torque densities are achievable owing to torque magnification achieved by air-gap profiling as well as flux concentration. Initial analysis indicates that this machine presents higher torque than a YASA machine, which currently holds a record for torque density.
\end{abstract}

Index Terms-Axial flux machine, yokeless motor, high polarity, spoke rotor, Vernier machine.

\section{INTRODUCTION}

Axial flux permanent magnet (AFPM) synchronous motors are recognized for their high specific torque and have been developed for diverse low speed direct systems, such as electric propulsion systems, generator sets and others [1]. One topology in particular, the yokless and segmented armature (YASA) [2] attracted substantial recent attention for its recordbreaking high torque density and interesting applications, including the powering of a 1,500 bhp hypercar [3].

The torque output of an AFPM machine can be increased, in principle, by the use of multiple stators and rotors. The arrangement with two stators and one rotor in between them is typically considered advantageous in terms of cooling the stators, where most of the losses are produced. Yet, it is a YASA design with a stator placed between two rotors in a north $(\mathrm{N})$ south $(\mathrm{S})$, opposite (NS) polarity arrangement that sets a record for torque density.

Increases in torque output could be also achieved through air-gap flux modulation techniques, such as those employed by split tooth machines [4] and Vernier type machines, e.g. [5]-[10]. Such machines incorporate magnetic gearing effects, leading to torque magnification. Recent AFPM machine example developments in this respect include an NN type with one stator sandwiched between two surface PM rotors [11], and a dual stator with a single spoke type central rotor [12]. A special note is due for a triple rotor dual stator AFPM, with one spoke type central rotor and two surface PM end rotors, which achieves not only high torque density, but also reasonably high power factor, overcoming therefore, to some extent, one of the inherent limitations of conventional Vernier machines [13].

The present paper brings further contributions by proposing a novel topology, referred to as MAGNUS due to its torque magnification characteristics, obtained by combining a YASA central stator type NS arrangement with two external spokerotors that have extremely high polarity and hence a very high flux focusing effect. It is remarkable that only a reduced number of main stator teeth, each carrying a single concentrated winding, are employed as in the flux reversal machine of [14]. Operation with a very high number of rotor poles is yet possible due to a special profiling of the stator inner surface through small notches that effectively create additional smaller stator teeth and modulate the air-gap magnetic flux. Combinations of 6 and 12 coils and as many as 44 poles are illustrated in the paper, representing an extremely high ratio previously not reported in the literature. Furthermore, the mathematical relationships between the large and small teeth and the rotor poles are systematically introduced and tabulated. Variations of the north-north (NN) type using concentrated or Gramme ring type windings are discussed and comparatively studied together with a conventional YASA reference design.

The primary applications for the MAGNUS machine remain the very low speed direct drive systems, for which the power factor is not typically a major concern as the electrical machine is of substantially large physical size and has higher cost than the power electronics. Nevertheless, the recent developments in wide band gap semiconductor device technology [15], may enable the use of the proposed high polarity ultra-high specific torque machine topologies for higher speed applications. 


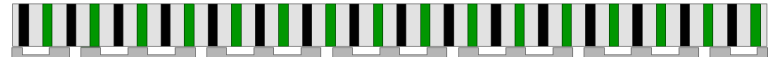 IIIIIIIIIIIIIIIIIIIIIIIIII}

Fig. 1. "Unrolled" 2D view of an example proposed axial flux machine PM (AFPM) machine of the MAGNUS type, which achieves very high specific torque by combining the use of a 32 pole spoke rotor with air-gap stator side profiling via small auxiliary teeth for permeance and flux modulation and with 6 concentrated coils around the main teeth of a yokeless segmented armature (YASA) stator

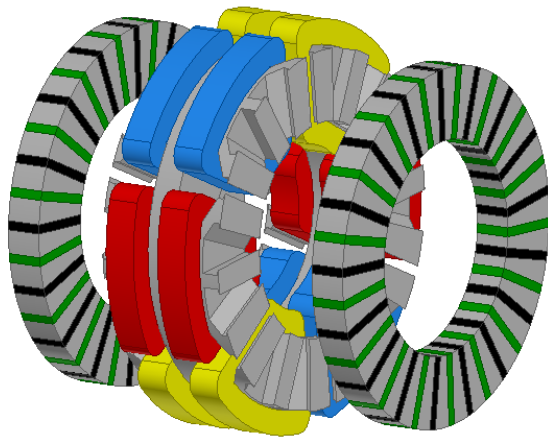

Fig. 2. Three dimensional model and an NN version of the MAGNUS topology employing a reduced number of concentrated coils in combination with a very large number of rotor poles.

\section{Machine Structure And Operating Principle}

The developed view of a single stator dual rotor NS type design and 3D rendering of an NN type machine with similar topology are presented (Fig. 1 and Fig. 2). In case of the NS type machine, the segmented stator teeth can be assembled with the help of annular plates on two sides of the stator disc [16]. The stator teeth have concentrated coils. Each of the large teeth includes 3 smaller teeth, crucial in achieving torque magnification. Torque magnification can be understood by considering the geometry of a 6-slot 4-pole PMSM (Fig. 3). Surface PM implementations of the proposed machine are used

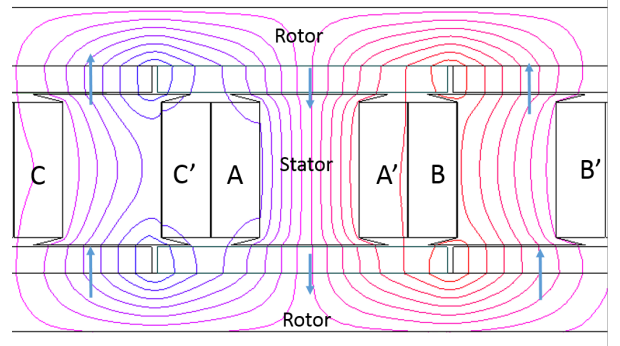

Fig. 3. Flux lines as obtained from two-dimensional finite element analysis for a 6-slot 4-pole PMSM with fractional slot concentrated winding. Only one PM contributes to the flux linkage of a coil.

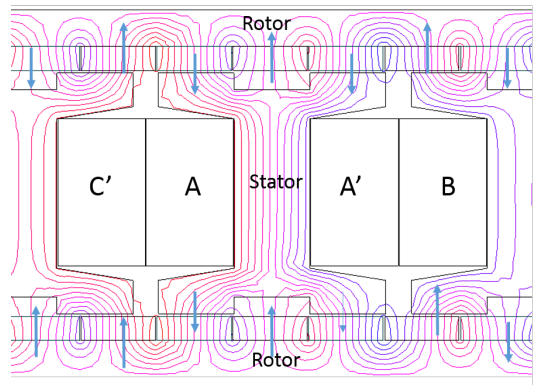

Fig. 4. Open circuit flux lines for a 6-slot 20-pole machine. In this machine with 2 auxiliary stator teeth per main tooth, two PMs contribute to flux linkage of a coil.

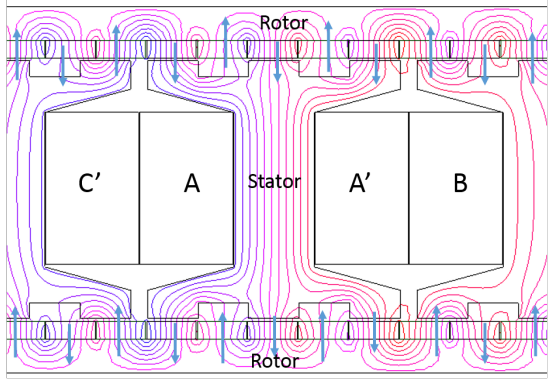

Fig. 5. Field lines on open circuit for a 6-slot 32-pole machine with 3 auxiliary stator teeth. Three PMs contribute to the coil flux linkage. The auxiliary slots prevent flux from the PM of opposite polarity from linking with the coil.

to explain the operating principle of the machine. In Fig. 3, the flux linked by Phase $\mathrm{A}$ is at its maximum, and it is noticed that only one magnet contributes to the flux linked by one phase coil. The flux linked by a phase, consisting of two coil sides may be expressed as

$$
\psi_{m}=2 \frac{\left(D_{o}-D_{i}\right)}{2} w_{s} B_{g}=\left(D_{o}-D_{i}\right) k \frac{\pi D_{m}}{P_{r}} B_{g},
$$

where, $w_{s}$ is the width of the stator tooth tip; $P_{r}$, the number of rotor poles; $D_{m}, D_{o}, D_{i}$, the mean, outer, inner diameters, respectively; and $\mathrm{k}$, the ratio of stator tooth tip width to the pole pitch.

For a machine with 2 auxiliary stator teeth per main tooth (Fig. 4), it is seen that there are three PMs facing a stator tooth, and two of them contribute to the flux linkage of one phase coil. The total width of the stator tooth tip, with each of the auxiliary teeth as wide as the rotor pole pitch is hence three times the pole pitch. The PM flux linked by a phase is given as

$$
\psi_{m}=\left(D_{o}-D_{i}\right) \frac{2}{3} w_{s} B_{g}=2\left(D_{o}-D_{i}\right) \frac{\pi D_{m}}{P_{r}} B_{g} .
$$

Likewise, for a machine with 3 auxiliary stator teeth per main tooth, three PMs result in useful phase flux linkage (Fig. 5). In this case, the phase flux due to the PMs is

$$
\psi_{m}=3\left(D_{o}-D_{i}\right) \frac{\pi D_{m}}{P_{r}} B_{g} .
$$


The torque with a pure q-axis excitation for all the machines is expressed as

$$
T=\frac{3 P_{r}}{4} \psi_{m} I_{q}
$$

This yields, for the 6-slot 4-pole machine considered above,

$$
T_{1}=\frac{3}{4}\left(D_{o}-D_{i}\right) k \pi D_{m} B_{g} .
$$

It may be noted here that if a 12-slot 8-pole or 24-slot 16pole machine is employed in place of a 6-slot 4-pole machine, the torque would remain unchanged as the increase in torque due to increase in $P_{r}$ is compensated for by a proportionate reduction in $\psi_{m}$, as (1) indicates. However, in case of the multiple teeth machines, the torque may expressed as

$$
T_{2}=\frac{3}{4}\left(D_{o}-D_{i}\right) 2 \pi D_{m} B_{g}
$$

and

$$
T_{3}=\frac{3}{4}\left(D_{o}-D_{i}\right) 3 \pi D_{m} B_{g},
$$

where, $T_{1}, T_{2}$ and $T_{3}$ are the torques produced by the 6-slot 4-pole machine, and the multi-tooth machines with 2 and 3 auxiliary stator teeth per main tooth, respectively. For the same dimensions and magnet type, the ratio of the torque produced by a machine with 4 poles and 6 slots with 2 auxiliary per main tooth is given, bearing in mind that $\mathrm{k}$ is at the most $\frac{2}{3}$, as

$$
\frac{T_{2}}{T_{1}}=\frac{\frac{3}{4}\left(D_{o}-D_{i}\right) 2 \pi D_{m} B_{g}}{\frac{3}{4}\left(D_{o}-D_{i}\right) k \pi D_{m} B_{g}}=3 .
$$

Similary, for the machine with 3 auxiliary teeth, one can obtain

$$
\frac{T_{3}}{T_{1}}=\frac{\frac{3}{4}\left(D_{o}-D_{i}\right) 2 \pi D_{m} B_{g}}{\frac{3}{4}\left(D_{o}-D_{i}\right) k \pi D_{m} B_{g}}=4.5 .
$$

This analysis indicates that if the same dimensions are employed, the torque of a 6 tooth motor triples when 2 auxiliary teeth per main tooth are employed, and increases four times with the use of 3 auxiliary teeth per main tooth. This increase in torque due to the increase in the number of active permanent magnets will henceforth be referred to as torque magnification in this paper.

A wide array of slot-pole combinations may be employed for this machine. The number of rotor poles required for a three phase machine are obtained by considering two constraints: 1) there must be an odd number of PM poles facing each stator tooth, and 2) $\pm 120^{\circ}$ phase shift is desired between the phases. The first of these conditions ensures that only PM poles of one polarity contribute to phase flux linkage at a given time. These may be expressed as

$$
P_{r}>n T_{s}
$$

where, $P_{r}$ is the number of rotor poles, $T_{s}$, the number of main stator teeth and $\mathrm{n}$ is given in terms of the number of auxiliary stator teeth $\left(t_{s}\right)$ as

$$
n=2 t_{s}-1
$$

The second condition is expressed as

$$
P_{r}=\frac{2}{3} T_{s} k_{1}
$$

where, $k_{1}$ may take all values, except 3 and its multiples. For a machine having 6 main stator teeth, with 2 auxiliary teeth, the first value of $P_{r}$ satisfying both of the above is 20 .

The operating principle of the machine can also be understood by considering that a harmonic component of the winding MMF interacts with the rotor MMF to produce synchronous torque. The torque producing harmonic component is enhanced by the main and auxiliary stator teeth. Thus, the relation between the main stator teeth, auxiliary teeth armature $\left(P_{a}\right)$ and PM poles may also be obtained, using trigonometry, as

$$
T_{s} \times t_{s}=\frac{P_{a}+P_{r}}{2} .
$$

Some feasible slot and teeth combinations are provided in Table I. It should be noted that the auxiliary stator teeth on one main stator tooth must be in the same position with respect to the rotor PMs to ensure maximum flux linkage by the phase winding. This is ensured by maintaining

$$
t_{\text {slot }}=2-t_{\text {tooth }},
$$

where, $t_{\text {slot }}$ and $t_{\text {tooth }}$ are the ratios of auxiliary slot and auxiliary tooth widths to the PM pole pitch, respectively.

\section{Equivalent 2-D Finite Element Modeling}

Two-dimensional finite element analysis (FEA) at the mean diameter is used to verify the performance improvement for the surface mounted PM (SPM) topologies as predicted by the simplified analysis. The high polarity split tooth machines demonstrate a significant increase in torque, upto twice (Table II), although not as dramatic as indicated by the preliminary analysis. This is because the air-gap flux density reduces with increasing number of rotor poles due to higher leakage (Table II), a fact neglected by the simplified analysis. It is also noticed that the 32 pole machine with 3 auxiliary teeth has $15 \%$ higher torque than the 20 pole machine with only two auxiliary teeth per main stator tooth. About a $50 \%$ increase in torque should have been achieved, but it is compensated for in part by a reduction in the axial component of air-gap flux density.

It may be noted that increase in torque is due to a combination of the torque magnification effect and high rotor polarity. The use of a larger number of rotor poles reduces the flux per pole, and therefore the dimensions of different parts of the magnetic circuit may be reduced, allowing more room for conductors. This allows the use of larger conductor cross sections, which has the effect of reducing the copper loss. Alternatively, higher armature MMF can be employed, increasing the torque output.

The lower flux density imposed by surface mounted PMs is corrected by employing flux concentration using spoke PMs in the proposed machine. Finite element analysis shows that this has the effect of increasing the average axial component of air-gap flux density from $0.77 \mathrm{~T}$ to $1.3 \mathrm{~T}$, thereby increasing 
TABLE I

EXAMPLE FEASIBLE COMBINATIONS OF NUMBER OF MAIN, AUXILIARY TEETH AND ROTOR POLES. INTEGRAL MULTIPLES OF THESE COMBINATIONS CAN ALSO BE USED.

\begin{tabular}{c|ccc}
\hline & Auxiliary stator teeth & Rotor Poles & Winding factor \\
\hline \multirow{2}{*}{6 main teeth and 4 armature poles } & 2 & 20 & 0.866 \\
& 3 & 32 & 0.866 \\
& 4 & 44 & 0.866 \\
\hline \multirow{2}{*}{9 main teeth and 6 armature poles } & 2 & 30 & 0.866 \\
& 3 & 48 & 0.866 \\
\hline NN AFPM with Gramme ring windings, & 4 & 66 & 0.866 \\
6 main teeth and 2 armature poles & 3 & 22 & 1.000 \\
& 4 & 34 & 1.000 \\
\hline
\end{tabular}

TABLE II

TWO-DIMENSIONAL FEA BASED COMPARISON OF SPM MACHINES WITH 6 Main STATOR TEETH INCLUding 1, 2 AND 3 AUXiLiary TEETH. AlL MACHINES HAVE THE SAME COPPER LOSS.

\begin{tabular}{ccc}
\hline Machine Topology & $\begin{array}{c}\text { Air gap flux density } \\
{[\mathrm{T}]}\end{array}$ & $\begin{array}{c}\text { Torque } \\
{[\mathrm{Nm}]}\end{array}$ \\
\hline 6-slot 4-pole & 0.93 & 100 \\
6-slot 20-pole & 0.82 & 194 \\
6-slot 32-pole & 0.77 & 224 \\
\hline
\end{tabular}

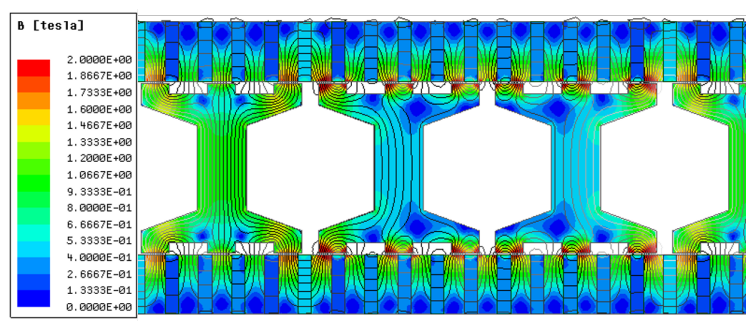

Fig. 6. Open circuit flux density distribution and flux lines for the MAGNUS machine.

torque. Two dimensional field plots for the spoke machine with 6 slots and 32 poles are included to facilitate visualization and explanations as 3D representations would be more difficult to follow (Fig. 6).

The induced EMFs confirm the operation of the machine (Fig. 7a). Due to the relatively large number of poles, the machine presents negligible torque due to saliency and is therefore operated much like SPM machine, i.e. the phase currents are aligned with the open-circuit back EMF. Owing to the somewhat large inductance, the currents present a very small switching ripple even at the relatively low PWM frequency of $1 \mathrm{kHz}$ (Fig. 7b). The torque with switching ripple including shows little ripple of about 10\% (Fig. 7c).

\section{Other Slot Pole Combinations AND Their EFFECT}

The slot pole combinations listed in Table I attest to the fact that such machine topologies may be realized over a wide range of slot pole combinations. To observe the effect of increasing number of auxiliary teeth, the 6-slot 32-pole topology with $t_{s}=3$ is compared with a 6-slot 20-pole topology with $t_{s}=2$, and a 6 -slot 44-pole topology with $t_{s}=4$.

The 6-slot 32-pole spoke machine has the highest efficiency for the same output among the compared 6 main stator teeth topologies (Table III). The torque improvement of the 32 and 44 pole topologies over the 6-slot 20-pole topology is due to the torque magnification effect, as well as higher flux concentration. Although the 6-slot 44-pole machine would in principle have larger flux concentration than the other topologies considered, it produces the same torque as the 6slot 32-pole for the same copper loss. This might be due to saturation of the rotor steel at the higher flux concentration, and also the higher leakage flux associated with a large number of rotor poles as also evidenced by the declining power factor. This analysis indicates that there is an upper limit to the improvements, owing to leakage, saturation and core loss that can be achieved by increasing the number of auxiliary stator teeth and rotor poles for a given number of main stator teeth.

Included in the comparison is a 12-slot 40-pole machine, which is obtained by doubling the 6-slot 20-pole topology. The higher flux concentration and smaller end winding volume contribute to smaller copper loss. It has the highest power factor and efficiency of all the compared topologies. Topologies with a larger number of main stator teeth might be a suitable choice in applications which have a constraint on the overall diameter.

The spoke PM machine with two rotors has a limitation that only one side of the spoke rotor is used for torque production. Another implementation, with a single central rotor and two stators shifted by $180^{\circ}$ elec. allows use of both sides of the spoke rotor [17]. This machine produces the same output for lower copper loss (Table I), although the core loss is much higher than the 2 rotor topologies, implying a better utilization of the magnetic circuit.

The MAGNUS topology may also be realized as an NN type with Gramme ring winding (Fig. 8) which mimics a distributed winding and for a 12-slot configuration, a 4-pole winding with a fundamental winding factor of 1 may be achieved. This topology, when implemented with $t_{s}=2$ would need to have 44 rotor poles (Table I). The addition of two auxiliary 


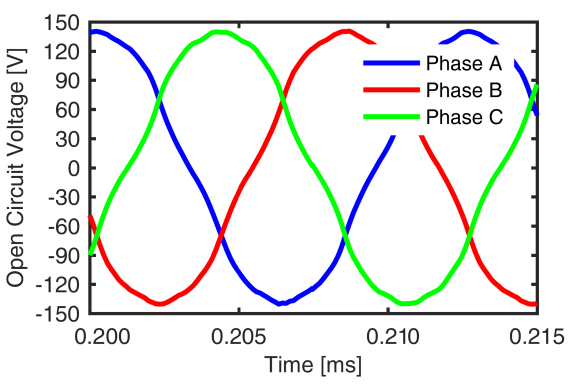

(a)

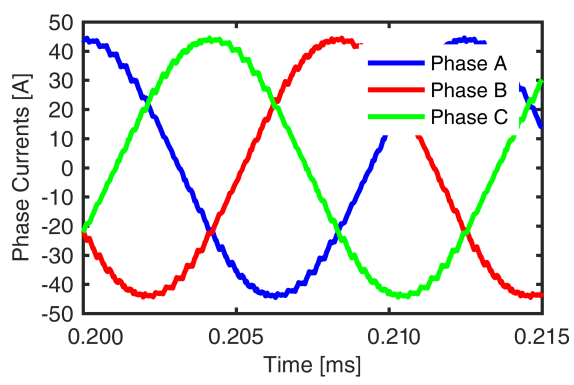

(b)

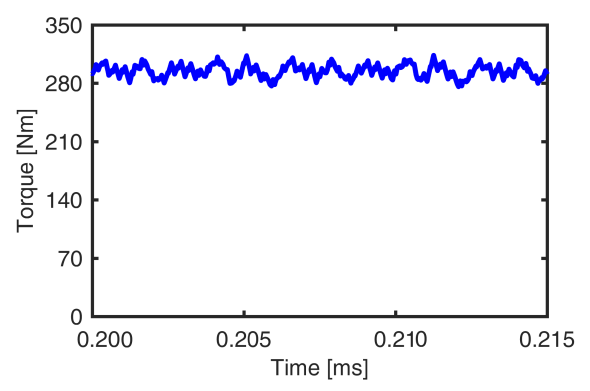

(c)

Fig. 7. (a) Open circuit back emf, (b) phase currents with a switching frequency of $1 \mathrm{kHz}$, and (c) torque ripple including inverter switching and cogging torque. The currents present very small ripple owing to the rather large inductance of this machine, even at the relatively low switching frequency. The peak to peak torque ripple is $10 \%$.

TABLE III

COMPARATIVE DESIGN STUDY OF TOPOLOGICAL VARIATIONS FOR THE PROPOSED MAGNUS MACHINE. ALL THE STUDIED TOPOLOGIES HAVE THE SAME ACTIVE DIMENSIONS AND ARE DESIGNED FOR THE SAME TORQUE OF 270 NM AT THE RATED SPEED OF 300 RPM.

\begin{tabular}{ccccc}
\hline Machine topology & $\begin{array}{c}\text { Copper Loss } \\
{[\mathrm{W}]}\end{array}$ & $\begin{array}{c}\text { Core Loss } \\
{[\mathrm{W}]}\end{array}$ & $\begin{array}{c}\text { Electrical Efficiency } \\
{[\%]}\end{array}$ & Power factor \\
\hline 6-slot 20-pole & 548 & 126 & 92.5 & 0.75 \\
6-slot 32-pole & 378 & 172 & 93.8 & 0.64 \\
6-slot 44-pole & 378 & 290 & 92.6 & 0.46 \\
12-slot 40-pole & 265 & 224 & 94.5 & 0.75 \\
6-slot 32-pole with 2 stators & 283 & 320 & 93.5 & 0.68 \\
12-slot 44-pole (Gramme ring windings) & 378 & 248 & 93.1 & 0.62 \\
12-slot 44-pole (Gramme ring windings and aux. stators) & 256 & 398 & 92.9 & 0.64 \\
12-slot 10-pole conventional YASA & 946 & 56 & 89.2 & 0.90 \\
\hline
\end{tabular}

stators without coils on the free side of each spoke rotor leads to reduced leakage (Fig. 9a and 9b) and higher torque for the same copper loss, albeit with increased manufacturing complexity and core loss. The two auxiliary stators are shifted with respect to the main stator by 180 electrical degrees.

\section{COMPARISON WITH a CONVENTIONAL NS AFPM TOPOLOGY}

For benchmarking the performance of the MAGNUS machines, they are compared with an NS type AFPM machine with 12 slots and 10 poles. The developed view of this topology is shown in Fig. 10a. This NS type AFPM is also known as YASA, one of the most torque dense machines [2]. This machine is designed with the same active dimensions, and its performance with the multiple tooth motor topologies is compared at the output torque of $270 \mathrm{Nm}$, and $300 \mathrm{rpm}$. The open circuit flux lines indicate that the flux densities in different parts of the magnetic circuit are higher, indicating better utilization of the PMs (Fig. 10b).

To produce the same torque, the 12-slot 10-pole machine needs to have much higher copper loss (about 1.7 - 3.5 times) than the multiple teeth machine topologies (Table III). The core losses are much lower than in all the other topologies due to lower number of poles.

\section{CONCLUSiOnS}

A novel motor topology is introduced under the name of MAGNUS. The proposed configuration employs a combi-

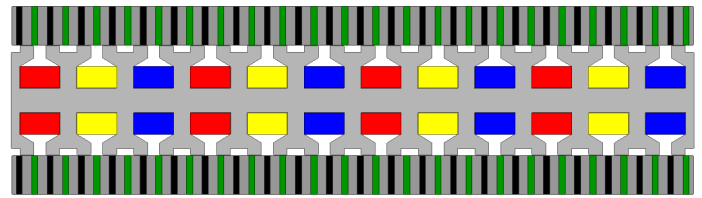

(a)

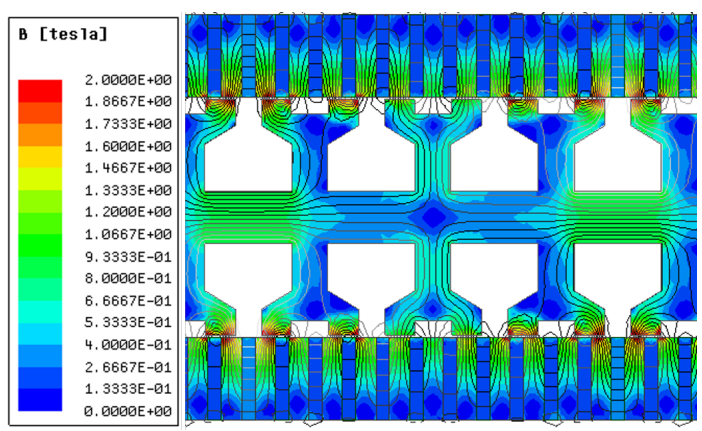

(b)

Fig. 8. (a) Design variation for the NN type of the MAGNUS machine employing concentrated coils wound around the yoke in a Gramme ring winding arrangement, (b) with its flux density distribution on open circuit.

nation of exterior high-polarity PM rotors together with an interior stator, which is profiled on the air-gap sides through the addition of small auxiliary teeth for permeance and flux modulation. Two stator configurations with reduced number 


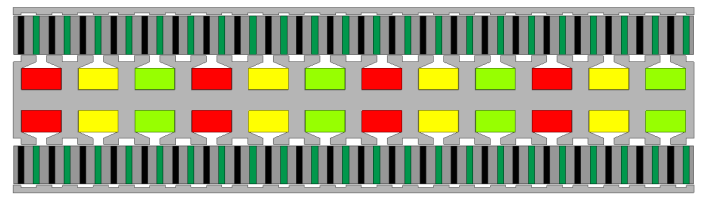

(a)

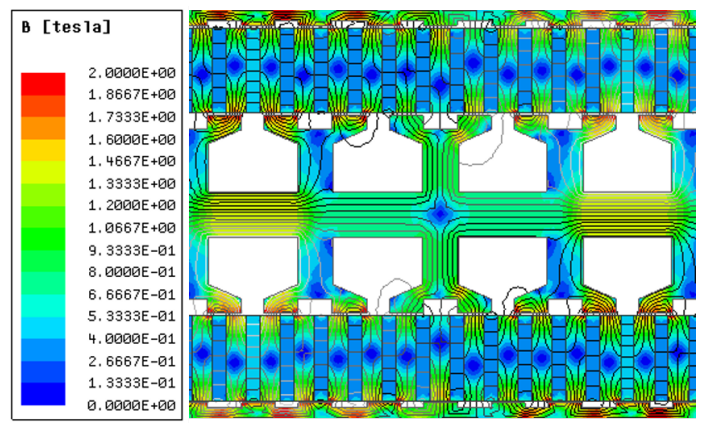

(b)

Fig. 9. (a) Geometry with the addition of two auxiliary stators on the unused sides of the spoke rotors, and (b) flux lines on open circuit with the auxiliary stators. Increase in flux density in the main stator core is observed, indicating that flux linked by the coil increases.

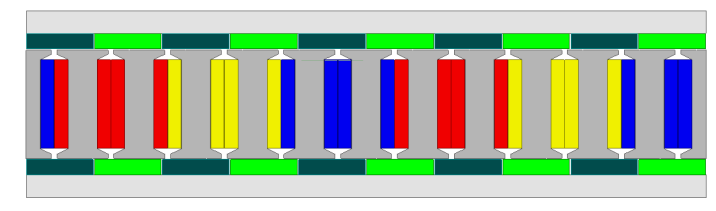

(a)

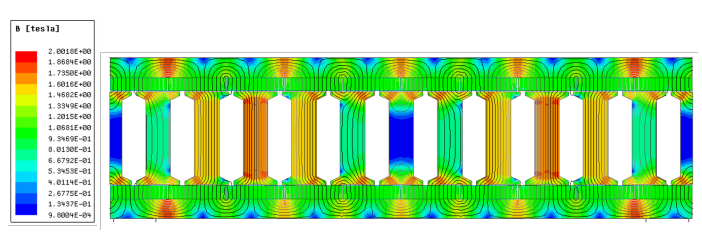

(b)

Fig. 10. (a) Developed view of a YASA AFPM machine with 12 slots and 10 poles, which claims a record breaking value for power density, (b) open circuit flux density distribution.

of coils were considered. In one version, coils are placed around the main stator teeth in a yokeless segmented armature arrangement of the YASA type, and in another construction Gramme "drum" type coils are placed around the stator back iron. Low speed high-torque motor designs are exemplified in an axial flux arrangement with spoke rotors. Ferrite magnets may also be used due to the high flux concentration.

The relationship between the rotor poles and the stator main and auxiliary teeth and winding patterns with concentrated coils has been identified and feasible combinations are tabulated for 3-phase motor examples with up to 12 coils and up to 66 poles. Mathematical derivations show that the proposed MAGNUS machines realize, in principle a torque magnification, and can achieve a substantial increase in specific torque over their conventional PM synchronous motor counterparts. An example design study for the same active dimensions and $270 \mathrm{Nm}$ torque output at a rated speed of 300rpm indicates that MAGNUS machines can have half the losses of conventional YASA machines and hence achieve substantially higher efficiency

\section{ACKNOWLEDGMENT}

The support of University of Kentucky, the L. Stanley Pigman endowment and the SPARK program, and of ANSYS Inc. is gratefully acknowledged.

\section{REFERENCES}

[1] F. G. Capponi, G. D. Donato, and F. Caricchi, "Recent advances in axial-flux permanent-magnet machine technology," IEEE Transactions on Industry Applications, vol. 48, no. 6, pp. 2190-2205, Nov 2012.

[2] T. J. Woolmer and M. D. McCulloch, "Analysis of the yokeless and segmented armature machine," in 2007 IEEE International Electric Machines Drives Conference, vol. 1, May 2007, pp. 704-708.

[3] "YASA motors," http://www.yasamotors.com/yasa-powers-recordbreaking-hypercar/.

[4] B. Mecrow and A. Jack, "A new high torque density permanent magnet machine configuration," IEEE International Conference on Electric Machines and Drives, pp. 1046-1052, May 1990.

[5] F. Zhao, T. A. Lipo, and B. I. Kwon, "A novel dual-stator axialflux spoke-type permanent magnet vernier machine for direct-drive applications," IEEE Transactions on Magnetics, vol. 50, no. 11, pp. 1-4, Nov 2014.

[6] D. Li, R. Qu, and T. A. Lipo, "High-power-factor vernier permanentmagnet machines," IEEE Transactions on Industry Applications, vol. 50, no. 6, pp. 3664-3674, Nov 2014.

[7] L. Xu, G. Liu, W. Zhao, X. Yang, and R. Cheng, "Hybrid stator design of fault-tolerant permanent-magnet vernier machines for directdrive applications," IEEE Transactions on Industrial Electronics, vol. 64, no. 1, pp. 179-190, Jan 2017.

[8] H. Fujinaka, "Brush-less motor using vernier structure," Patent US 7,064,468, Jun., 2006.

[9] K. Okada, N. Niguchi, and K. Hirata, "Analysis of a vernier motor with concentrated windings," IEEE Transactions on Magnetics, vol. 49, no. 5, pp. 2241-2244, May 2013.

[10] J. Li, K. T. Chau, J. Z. Jiang, C. Liu, and W. Li, "A new efficient permanent-magnet vernier machine for wind power generation," IEEE Transactions on Magnetics, vol. 46, no. 6, pp. 1475-1478, June 2010.

[11] X. Luo, S. Niu, and W. N. Fu, "Design and sensorless control of a novel axial-flux permanent magnet machine for in-wheel applications," IEEE Transactions on Applied Superconductivity, vol. 26, no. 7, pp. 1-5, Oct 2016.

[12] F. Zhao, T. A. Lipo, and B. I. Kwon, "A novel dual-stator axialflux spoke-type permanent magnet vernier machine for direct-drive applications," IEEE Transactions on Magnetics, vol. 50, no. 11, pp. 1-4, Nov 2014.

[13] R. Zhang, J. Li, R. Qu, and D. Li, "A novel triple-rotor axial-flux vernier permanent magnet machine," IEEE Transactions on Applied Superconductivity, vol. 26, no. 7, pp. 1-5, Oct 2016.

[14] I. Boldea, J. Zhang, and S. A. Nasar, "Theoretical characterization of flux reversal machine in low-speed servo drives-the pole-pm configuration," IEEE Transactions on Industry Applications, vol. 38, no. 6, pp. 15491557, Nov 2002.

[15] J. Biela, M. Schweizer, S. Waffler, and J. W. Kolar, "SiC versus $\mathrm{Si}$; evaluation of potentials for performance improvement of inverter and DC DC converter systems by SiC power semiconductors," IEEE Transactions on Industrial Electronics, vol. 58, no. 7, pp. 2872-2882, July 2011.

[16] B. Zhang, T. Seidler, R. Dierken, and M. Doppelbauer, "Development of a yokeless and segmented armature axial flux machine," IEEE Transactions on Industrial Electronics, vol. 63, no. 4, pp. 2062-2071, April 2016.

[17] V. Rallabandi, N. Taran, D. M. Ionel, and I. G. Boldea, "Axial flux permanent magnet synchronous machine with air-gap profiling and large ratio of spoke PM poles to concentrated coils," IEEE International Conference on Electric Machines and Drives, May 2017. 